\title{
Modelling Study on Stiffness Characteristics of Hydraulic Cylinder under Multi-Factors
}

\author{
Hao Feng $1,2,{ }^{*}$ - Qungui Du ${ }^{1}$ - Yuxian Huang 3 - Yongbin Chi ${ }^{1}$ \\ 1 South China University of Technology, School of Mechanical \& Automotive Engineering, China \\ 2 Liugong Machinery Co., Ltd, R\&D Center, China \\ 3 Purdue University, Herrick Laboratories, School of Mechanical Engineering, USA
}

\begin{abstract}
For a complex mechanical system driven by hydraulic cylinders, the dynamic response characteristics of the mechanical system are significantly affected by the stiffness characteristics of hydraulic cylinders. This paper comprehensively studies the impacts of various factors on the stiffness characteristics of the hydraulic cylinders, including the oil bulk modulus, the air content in the hydraulic oil, the axial deformation of the piston rod, the volume expansion of the cylinder barrel, the volume expansion of the metal pipes and the flexible hoses, and the deformation of the hydraulic cylinder sealing. By combining the theoretical analysis and the experimental results, the level of each impacting factor was quantified, and the stiffness model of the hydraulic cylinder was established. Finally, comparative analysis of the stiffness was conducted by taking the experimental hydraulic cylinder as an example; it was verified that the calculated results of the proposed hydraulic cylinder stiffness model approximated the experimental results. Compared with stiffness models presented in current literature, the average accuracy was improved by more than $15 \%$.
\end{abstract}

Keywords: hydraulic cylinder stiffness, bulk modulus, air content in hydraulic oil, hydraulic system

Highlights

- A new stiffness model of the hydraulic cylinder was established, which incorporated factors of the compressibility of the oil, the axial deformation of the piston rod, the volume expansion of cylinder barrel, and the volume expansion of flexible hoses.

- The level of each impacting factor on the hydraulic cylinder stiffness was analysed: the compressibility of the oil is about $80 \%$, the volume expansion of the cylinder barrel is about $10 \%$, the axial deformation of the piston rod is about $6 \%$, and the volume expansion of flexible hoses is about $3 \%$. The impact of either the volume expansion of metal pipes or the sealing deformation is very small.

- Experimental tests proved that the content of the air in the hydraulic oil influences both the hydraulic cylinder stiffness and the bulk modulus significantly, but only at a low pressure level $(P<6 \mathrm{MPa})$.

- $\quad$ Tests proved that the change of the hydraulic cylinder stiffness is nonlinear. When the pressure $P<6 \mathrm{MPa}$, the degree of nonlinearity is relatively high. However, when the pressure is $P>6 \mathrm{MPa}$, the stiffness approaches to linearity.

\section{O INTRODUCTION}

Hydraulic cylinders are widely used in mechanical systems to drive loads. However, their stiffness characteristics significantly affect the characteristics of system dynamics [1] to [4]. Several studies have been carried out to date. For example, Dai [5], Wang and $\mathrm{Wu}$ [6] and Khalil [7] proposed the stiffness model described by Eq. (1). Laceklis-Bertmanis et al. [1] also adopted the aforementioned stiffness model to solve the vibration problem in a hydraulic hitch-system. However, when Zhong and Yunxin [8] calculated the dynamic response of a pump truck boom using Eq. (1), the impact of the axial deformation of the piston rod on the stiffness was also considered. Recently, the mathematical model of the hydraulic cylinder stiffness was established by Jiang et al. [9] and the flexibility of the fluid supply circular tubes was considered via the volume modulus of the circular tube. Meanwhile, the tests also demonstrate that the stiffness of the hydraulic cylinder is significantly impacted by the flexibility of the circular fluid supply tubes:

$$
K=E_{o}\left[\frac{A_{1}^{2}}{V_{1}+V_{L 1}}+\frac{A_{2}^{2}}{V_{2}+V_{L 2}}\right],
$$

where $K$ is the stiffness of the hydraulic cylinder system, $E_{o}$ is the oil bulk modulus, $A_{1}$ and $A_{2}$ are the effective area of the head chamber and the rod chamber, $V_{1}$ and $V_{2}$ are the volume of the head chamber and the rod chamber, and $V_{L 1}$ and $V_{L 2}$ are the fluid line volume on the head chamber and on the rod chamber, respectively.

Most of the mathematical models for the stiffness calculation provided in the mentioned literature only considered the influences of certain factors. The compressibility of the hydraulic oil, the axial deformation of the piston rod, and the flexibility of the fluid supply circular tube were included, while the influences of the air content in the oil, the volume expansion of the cylinder barrel, and the hydraulic cylinder sealing were neglected. In this 
paper, the stiffness characteristics of the hydraulic cylinder are fully analysed by comprehensively considering the compressibility of the hydraulic oil, the air content in the oil, the axial deformation of the piston rod, the volume expansion of the cylinder barrel, the volume expansion of the metal pipes, the volume expansion of the flexible hoses, and the hydraulic cylinder sealing.

\section{STIFFNESS MODELLING}

A hydraulic cylinder system mainly consists of the cylinder barrel, the hydraulic oil, the piston sealing, the rod sealing, the piston rod, the flexible hose, and the metal pipe, as shown in Fig. 1.

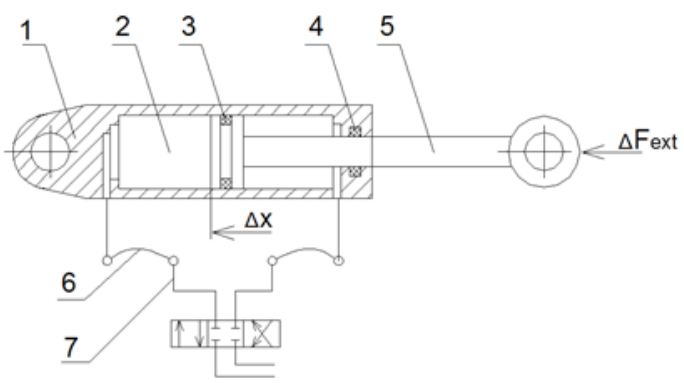

Fig. 1. A hydraulic system: 1 cylinder barrel, 2 hydraulic oil, 3 piston sealing, 4 rod sealing, 5 piston rod, 6 flexible hose, 7 metal pipe

The main factors affecting the hydraulic cylinder stiffness are the hydraulic oil stiffness $K_{o}$, the piston rod axial stiffness $K_{r}$, the cylinder barrel expansion stiffness $K_{c}$, the metal pipe expansion stiffness $K_{p}$, the flexible hose expansion stiffness $K_{h}$, and the sealing ring deformation stiffness $K_{s}$. The net stiffness can be regarded as the sum of the reciprocals of the stiffness of the individual component. Thus, the net stiffness $K$ of the hydraulic cylinder system can be calculated using Eq. (2):

$$
\frac{1}{K}=\frac{1}{K_{o}}+\frac{1}{K_{r}}+\frac{1}{K_{c}}+\frac{1}{K_{p}}+\frac{1}{K_{h}}+\frac{1}{K_{s}} .
$$

The stiffness modelling of each of the factors will be discussed in the next section.

\section{STIFFNESS MODELLING OF EACH INFLUENCING FACTOR}

\subsection{Axial Stiffness of the Piston Rod}

In general, the piston rod is a type of solid and cylindrical steel rod, and its stiffness can be determined by calculating the axial stiffness of the rod. The axial stiffness of the piston $\operatorname{rod} K_{r}$ is:

$$
K_{r}=\frac{E A_{r}}{L_{r}},
$$

where $A_{r}$ is the rod cross-sectional area, $L_{r}$ is the length of the piston rod, and $E$ is Young's modulus for the material of the piston rod. The axial stiffness of the piston rod is determined by its length and its rod cross-sectional area.

\subsection{Cylinder Barrel Expansion Stiffness}

The cylinder barrel expansion stiffness is produced by the movement of the piston rod, $\Delta x$, when the barrel of the hydraulic cylinder is expanded in the radial direction under a pressure change $\Delta P$. The formula for a steel cylinder radial deformation $\Delta D$ due to a pressure change $\Delta P$ is [10]:

$$
\Delta D=\frac{D \Delta P}{E_{b}}\left(\frac{D_{1}^{2}+D^{2}}{D_{1}^{2}-D^{2}}+v_{b}\right),
$$

where $E_{b}$ is Young's modulus for the cylinder barrel, $v_{b}$ is the Poisson ratio for the cylinder barrel, and $D_{1}$ and $D$ are the outer and inner diameters of the cylinder barrel, respectively.

Set $\frac{D_{1}^{2}+D^{2}}{D_{1}^{2}-D}=\lambda_{c}$ as the expansion coefficient. Then, Eq. (4) can be simplified as:

$$
\Delta D=\frac{D \Delta P}{E_{b}}\left(\lambda_{c}+v_{b}\right) .
$$

The volume expansion $\Delta V_{c 1}$ for the head chamber of the cylinder barrel under a pressure change $\Delta P$ is:

$$
\Delta V_{c 1}=\frac{\pi D \Delta D L_{1}}{2} .
$$

According to the formula of the spring stiffness $K_{s p}=d f / d x$, as well as Eqs. (5) and (6), the cylinder barrel expansion stiffness $K_{c 1}$ caused by the expansion of the head chamber is given by:

$$
K_{c 1}=\frac{\Delta P_{1} A_{1}}{\Delta S}=\frac{\Delta P_{1} A_{1}^{2}}{\Delta V_{c 1}}=\frac{E_{b} A_{1}}{2 L_{1}} \cdot \frac{1}{\lambda_{c}+v_{b}},
$$

where $\Delta P_{1}$ is the pressure change in the head chamber, and $L_{1}$ is the effective length of the head chamber.

Due to the difference between the cylinder effective cross-sectional area and the effective elongation, the stiffness calculations in terms of the deformation of the cylinder barrel between the head 
chamber and the rod chamber are different. Therefore, the cylinder effective cross-sectional area and the effective elongation of the rod chamber are defined as $A_{2}$ and $L_{2}$, while $A_{1}$ and $L_{1}$ in Eq. (7) are replaced by $A_{2}$ and $L_{2}$. Then the stiffness, $K_{c 2}$, of the rod chamber in terms of the deformation of the cylinder barrel can be obtained as:

$$
K_{c 2}=\frac{E_{b} A_{2}}{2 L_{2}} \cdot \frac{1}{\lambda_{c}+v_{b}} .
$$

\subsection{Metal Pipe Expansion Stiffness}

The metal pipe expansion stiffness is produced by the movement of the piston rod, $\Delta x$, when the metal pipe is expanded in the radial direction under a pressure change $\Delta P$.

The method to calculate the stiffness caused by the volume expansion of the metal pipe is the same as that of the cylinder barrel. Which, according to Eq. (4), can be derived as the radial deformation, $\Delta D_{p}$, of the metal pipe's inner diameter:

$$
\Delta D_{p}=\frac{D_{p} \Delta P}{E_{p}}\left(\frac{D_{p 1}^{2}+D_{p}^{2}}{D_{p 1}^{2}-D_{p}^{2}}+v_{p}\right)
$$

where $E_{p}$ is Young's modulus for the metal pipe, $v_{p}$ is the Poisson ratio for the metal pipe, and $D_{p 1}$ and $D_{p}$ are the outer and inner diameters of the metal pipe.

Set $\frac{D_{p 1}^{2}+D_{p}^{2}}{D_{p 1}^{2}-D_{p}^{2}}=\lambda_{p}$ as the expansion coefficient of the metal pipe. Then, the volume expansion, $\Delta V_{p}$, of the metal pipe under a pressure change $\Delta P$ is:

$$
\Delta V_{p}=\frac{\pi D_{p} \Delta D_{p} L_{p}}{2}
$$

where $L_{p}$ is the length of the metal pipe.

Thus, the stiffness $K_{p}$ caused by the expansion deformation of the metal pipe in the head chamber end is:

$$
K_{p}=\frac{\Delta P A_{1}}{\Delta V_{p} / A_{1}}=\frac{2 E_{p} A_{1}^{2}}{\pi D_{p}^{2} L_{p}\left(\lambda_{p}+v_{p}\right)} .
$$

\subsection{Flexible Hose Expansion Stiffness}

The flexible hose expansion stiffness is produced by the movement of the piston rod, $\Delta x$, when the flexible hose is expanded in the radial direction under a pressure change $\Delta P$.

The flexible hose is composed of an inner rubber layer, a medium steel wire winding, and an exterior anticorrosive rubber layer. The radial expansion of the flexible hose is nonlinear but small under a pressure change $\Delta P$. Hypothesis: i) The change in the radial direction is small and approximately linear. ii) An equivalent radial elasticity modulus, $E_{h}$, can be used to describe its small expansion. $E_{h}$ can be determined through experimental and theoretical methods. Therefore, the method for calculating the volume expansion of the hose is the same as that for the metal pipe.

Set $\frac{D_{h 1}^{2}+D_{h}^{2}}{D_{h 1}^{2}-D_{h}^{2}}=\lambda_{h}$ as the expansion coefficient of the flexible hose. Where $D_{h 1}$ and $D_{h}$ are the outer and the inner diameter of the flexible hose. Therefore, the stiffness, $K_{h}$, influenced by the expansion of the flexible hose in the head chamber end is:

$$
K_{h}=\frac{2 E_{h} A_{1}^{2}}{\pi D_{h}^{2} L_{h}\left(\lambda_{h}+v\right)},
$$

where $L_{h}$ is the length of the flexible hose.

Since the flexible hose is a type of multi-layer composite material, its complex properties need to be determined with the combined theoretical and experimental methodology. According to Eq. (2), the stiffness of the hydraulic cylinder without the flexible hose, $K_{\text {nohose }}$, is:

$$
\frac{1}{K_{\text {nohose }}}=\frac{1}{K_{o}}+\frac{1}{K_{r}}+\frac{1}{K_{c}}+\frac{1}{K_{p}}+\frac{1}{K_{s}} .
$$

According to Eq. (2), the stiffness of the hydraulic cylinder with the flexible hose $K_{\text {withhose }}$ is:

$$
\frac{1}{K_{\text {withhose }}}=\frac{1}{K_{o^{\prime}}}+\frac{1}{K_{r}}+\frac{1}{K_{c}}+\frac{1}{K_{p}}+\frac{1}{K_{h}}+\frac{1}{K_{s}} .
$$

By subtracting the Eq. (13) from the Eq. (14), the stiffness influenced by the volume expansion of the flexible hose and the compressibility of the oil in the flexible hose is given by:

$$
\frac{1}{K_{\text {withhose }}}-\frac{1}{K_{\text {nohose }}}=\frac{1}{K_{\text {oilhose }}}+\frac{1}{K_{h}} \text {. }
$$

According to Eq. (15), the stiffness, $K_{\text {withhose }}$, of the hydraulic cylinder with the flexible hose and the stiffness, $K_{\text {nohose }}$, of the hydraulic cylinder without the flexible hose can be measured. By combining Eqs. (12) and (15), the equivalent elasticity modulus of the flexible hose can be derived. 


\subsection{Stiffness of Hydraulic Oil}

According to the formula of the hydraulic oil's stiffness in [5] and [6], the stiffness, $K_{o}$, influenced by the hydraulic oil can be composed of the hydraulic oil's stiffness of the rod chamber and the head chamber.

$$
K_{o}=E_{o}\left(\frac{A_{1}^{2}}{V_{1}+V_{L 1}}+\frac{A_{2}^{2}}{V_{2}+V_{L 2}}\right) .
$$

The oil bulk modulus $E_{o}$ in Eq. (16) is influenced by the air content and the pressure of the fluid. There is a great deal of literature devoted to the study on the bulk modulus considering the influence of air content [14] to [17]. The oil bulk modulus $E_{o}$ considering the different air content rates and work pressures can be describe in Eq. (17), [16] and [17].

$$
E_{o}=E_{o}^{\prime} \cdot \frac{1+\alpha \cdot\left(\frac{p_{a}}{p_{a}+p}\right)^{1 / n}}{1+\alpha \cdot E_{o^{\prime}} \cdot \frac{p_{a}^{1 / n}}{n \cdot\left(p_{a}+p\right)^{(n+1) / n}}},
$$

wherein $E_{o}^{\prime}$ is the oil bulk modulus without air content $\alpha$ is the relative air content in oil under the atmospheric pressure; $p_{a}$ is the atmospheric pressure; $p$ is the working pressure, and $\mathrm{n}$ is the isentropic coefficient $(n=1.4)$.

\subsection{Stiffness Influenced by Sealing Deformation}

An external load impact will induce the axial reciprocating vibration of the hydraulic cylinder, so the seal ring will also follow in the reciprocating motion of the cylinder. Take the experimental hydraulic cylinder as an example in which a T-type bonded seal ring is used. The piston diameter is 160 $\mathrm{mm}$, the groove diameter is $145 \mathrm{~mm}$, and the side clearance of the groove is $0.2 \mathrm{~mm}$. As shown in Fig. 2 , the piston rod is subjected to an external force $F_{\text {ext }}$, and the rod chamber side is the high-pressure. When pushing the piston, the axial displacement of the seal ring, $\Delta x$, is about $0.2 \mathrm{~mm}$, and the extrusion output of the oil is $0.436 \mathrm{ml}$, corresponding to a calculated piston's displacement of $0.06 \mathrm{~mm}$. Note that the stiffness variation of the hydraulic cylinder influenced by the displacement of the seal ring is very small.

The step seal and the V-seal are two commonly adopted seals on the piston rod side. Moreover, the force exerted on the seal is unidirectional, and the self-deformation of the sealing is very small: so much so that the influence of the sealing ring deformation stiffness, $K_{s}$, on the stiffness mathematical model can be neglected.

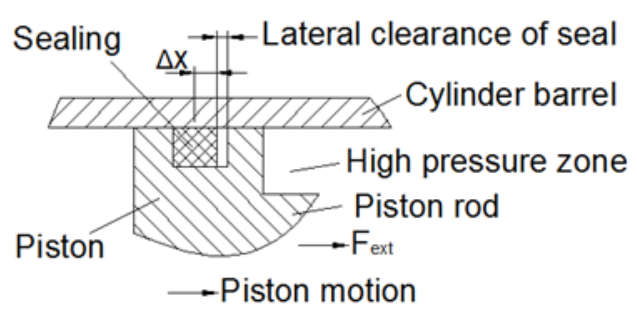

Fig. 2. The detailed section view of piston sealing

\section{EXPERIMENTAL TEST}

To measure the hydraulic cylinder stiffness, the equivalent elasticity modulus, $E_{h}$, of the flexible hose in Eq. (12) and the bulk modulus $E_{o}$ of the oil in Eq. (16), and to verify Eq. (2) of the hydraulic cylinder's stiffness mathematical model, the experimental study is carried out with the locked head chamber of the hydraulic cylinder. Moreover, the rod chamber of the cylinder is connected to the oil tank, shown in Fig. 3.

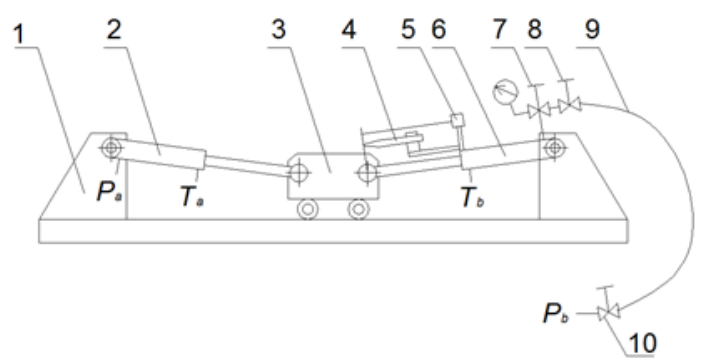

Fig. 3. Schematic of Experiment Setup: 1 platform, 2 loading hydraulic cylinder (LHC), 3 trolley, 4 magnetostrictive sensor, 5 draw wire displacement sensor, 6 experimental hydraulic cylinder (EHC), 7 vent valve, 8 cut-off valve, 9 flexible hose, 10 cut-off valve

Fig. 3 shows the experimental setup. The loading hydraulic cylinder (LHC) 2 and the experimental hydraulic cylinder (EHC) 6 are installed on the platform 1 and connected by the trolley 3. Two displacement sensors 4 and 5 are installed on the experimental hydraulic cylinder. The displacement sensor 4 is a high-precision magnetostrictive sensor that measures the compressive displacement variation of the hydraulic cylinder during the test, while the displacement sensor 5 is a draw-wire displacement sensor that measures the hydraulic cylinder stroke. $P_{b}$ is the pressure of the head chamber in the experimental hydraulic cylinder $6 . P_{a}$ and $T_{a}$ are the $P$ and $T$ port 
of the loading hydraulic cylinder 2. $P_{b}$ and $T_{b}$ are the $P$ and $T$ port of the experimental hydraulic cylinder 6. A flexible hose 9 is installed between the cut-off valves 8 and 10. Meanwhile, the discharge and intake of the air are carried out through the vent valve 7 , so that the influences of the different air contents on the stiffness of the hydraulic cylinder can be qualitatively studied. For easy air discharging, lower the height of the connecting trolley 3 to tilt the experimental hydraulic cylinder 6 and the air vent port 7 on the highest location of the hydraulic cylinder. Fig. 4 shows the actual testing devices. The technical data of the experimental setup is shown on Table 1. The residual volume $V_{r}$ in Table 1 refers to the oil volume in the tested air exhaust equipment and the hydraulic cylinder that cannot be calculated via the stroke.

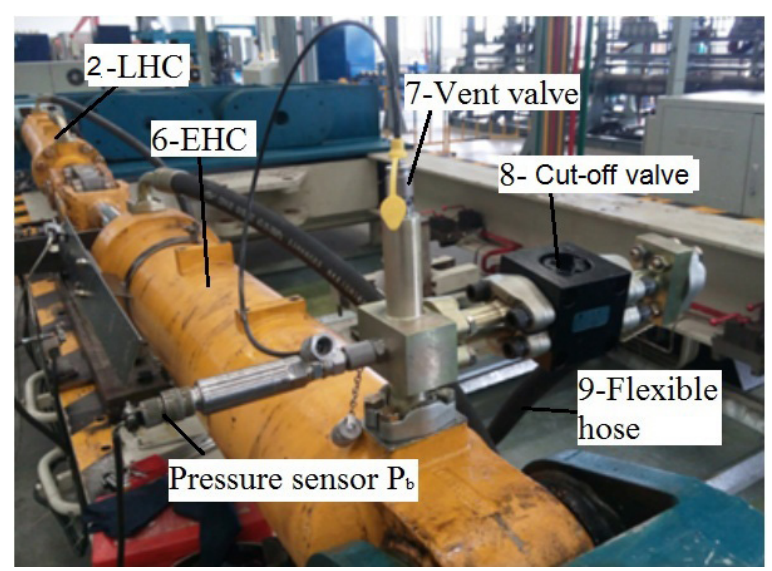

Fig. 4. The actual experimental setup

The oil leakage test must be done before the stiffness testing of the hydraulic cylinder. The test standards are the ISO standard [18] and [19]. The oil leakage caused by the piston seal must be less than $0.5 \mathrm{ml} / \mathrm{min}$ under the pressure of 1.5 times working pressure, and the pressure should be maintained for 2 $\min$.

Two conditions are considered for the state of the flexible hose: with or without the flexible hose, which is controlled through the cut-off valve 8, shown in Fig. 3.

Three different states are qualitatively considered for the air content: air content 0 is not considered in the discharged air; air content 1 is considered in the discharged air at the first time; and air content 2 is considered in the discharged air at the second time. By using the dissolving and releasing principle of the air in the hydraulic oil [11] and [12], and after multiple cyclic loading and unloading tests, the dissolved gas can be released as the undissolved gas. Then the air is discharged through the vent valve 7.

Table 1. Technical data of the experimental setup

\begin{tabular}{lc}
\hline Name & Value \\
\hline Cylinder barrel inner diameter [m] & 0.16 \\
\hline Cylinder barrel outer diameter [m] & 0.194 \\
\hline Piston rod diameter [m] & 0.08 \\
\hline Piston rod length [m] & 1.13 \\
\hline Cylinder maximum stroke [m] & 0.815 \\
\hline Flexible hose inner diameter [m] & 0.025 \\
\hline Flexible hose outer diameter [m] & 0.043 \\
\hline The length of flexible hose [m] & 2 \\
\hline The hydraulic oil type & L-HM46 \\
\hline The piston seal on the measuring hydraulic cylinder & Glyd Ring \\
\hline The residual volume, $V_{r}\left[\mathrm{~m}^{3}\right]$ & 0.001 \\
\hline
\end{tabular}

Five states are considered for evaluating the factor related to the hydraulic cylinder stroke: the following elongations of $0.138 \mathrm{~m}, 0.228 \mathrm{~m}, 0.381$ $\mathrm{m}, 0.456 \mathrm{~m}$, and $0.536 \mathrm{~m}$, respectively, and they are measured through the displacement sensor 5 .

The setup is carried out according to the factors related to the fluid line state, the air content, and the stroke before loading. During testing, the pressure $P_{b}$ of the testing hydraulic cylinder 6 and the compressive displacement of the displacement sensor 4 are acquired and collected in real time.

\section{RESULTS AND DISCUSSION}

\subsection{Analysis of Bulk Modulus \& Influence Factors}

To measure the oil bulk modulus and to qualitatively study the impact of the air content on the bulk modulus, the measured pressure and the displacement data are analysed according to the following conditions: (1) The flexible hose is neglected; (2) For the big elongation of the hydraulic cylinder and plenty of hydraulic oil, the elongation of the hydraulic cylinder is taken as $0.536 \mathrm{~m}$. (3) Consider the three different states of the air content. Because the amount of air discharges in the third test and afterwards is so small that it can be omitted, only the air discharges in the first two tests are considered in the data analysis and discussions. After data processing, the curve of the pressure-volume variation of the oil is obtained, and it is shown in Fig. 5.

From Fig. 5, the relation between the pressure and the volume variation is nonlinear, and the nonlinearity is particularly obvious at a low pressure. When the pressure $P>6 \mathrm{MPa}$, the relation becomes linear. At 
low pressure, the air content is obvious. When the pressure $P>6 \mathrm{MPa}$, the slopes under three states of the air content are approximately balanced, showing that the air influence on the bulk modulus is small at this time.

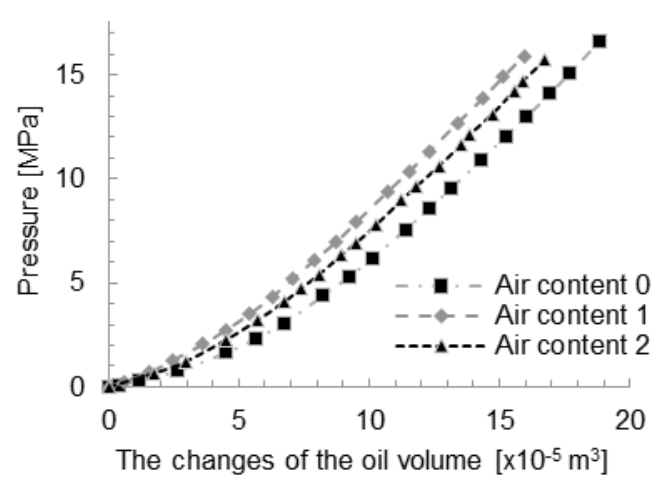

Fig. 5. The pressure-volume variation curve

According to the literatures [13] and [14], the oil's bulk modulus can be expressed as the tangent modulus or secant modulus. Thus, the tangent modulus and the secant modulus of the data in Fig. 5 are analysed, and the curve of the relation between the bulk modulus and the pressure is obtained and it is shown in Fig. 6 . The figure highlights that:

The bulk modulus of the hydraulic oil is nonlinear. When the pressure $P<6 \mathrm{MPa}$, the bulk modulus is greatly influenced by the air content, and the gradient of the variation is big. However, when the pressure $P>6 \mathrm{MPa}$ the air amount influences the bulk modulus less, and the linearity is obvious.

Since the working pressure of the hydraulic cylinder in a mechanical system is usually higher than $6 \mathrm{MPa}$ and considering that the secant bulk modulus is commonly adopted for transient variation of the stiffness $E_{o}=1.49 \mathrm{e} 9 \mathrm{~Pa}$ is taken according to Fig. 6, which is a value relatively approximated to the results given by Bureček in [16].

(2) At the three states of the air amount, the tangent bulk modulus is small because the tangent bulk modulus is calculated by $\Delta P_{i}$ and $\Delta V_{i}$, which are near the tangential direction, for examples: $\Delta P_{i}=P_{i+1}-P_{i-1}$ and $\Delta V_{i}=V_{i+1}-V_{i-1}$. Therefore, the relative pressure and the volume variation are used to calculate the bulk modulus, but the influence of the accumulated amount of the volume compression is not considered.

(3) At the three states of the air amount, the difference of the secant bulk modulus is obvious because the secant modulus is adopted to calculate $\Delta P_{i}=P_{i+1}-P_{0}$ and $\Delta V_{i}=V_{i+1}-V_{0}$, while the compressed volume of air $\Delta V_{\text {air }}$ is included in $\Delta V_{i}$.
Therefore, the larger the air volume in the hydraulic oil is, the bigger $\Delta V_{\text {air }}$ would be, leading to the increase of $\Delta V$, so the bulk modulus is small.

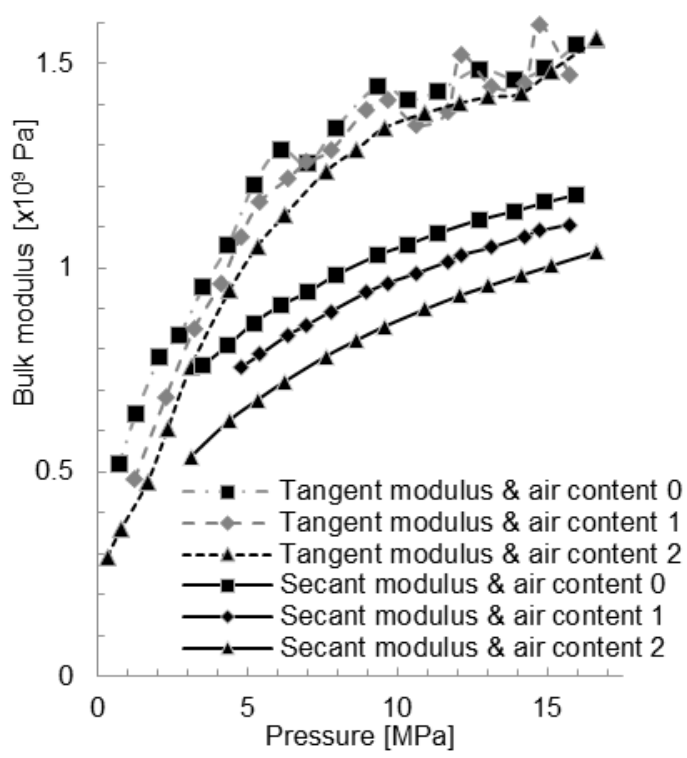

Fig. 6. The pressure-volume variation curve

\subsection{Stiffness Analysis of Hydraulic Cylinder and Influence Factors}

To measure the stiffness of the hydraulic cylinder and to qualitatively study the influence of the air content on the stiffness, measured pressure and displacement data are analysed according to the following conditions: (1) The flexible hose is considered. (2) For a large elongation of the hydraulic cylinder and plenty of hydraulic oil, the elongation of the hydraulic cylinder is taken as $0.536 \mathrm{~m}$. (3) Consider the three states of air content. After the data was processed, the curve of the hydraulic cylinder force-compressive displacement variation is obtained as shown in Fig. 7. The displacement in Fig. 7 was measured directly, while the piston force in Fig. 7 was converted from the measured pressure.

From Fig. 7, the curve approximates a pressurevolume variation curve of Fig. 5, showing that the characteristic of the hydraulic oil is the main factor for determining the stiffness of the hydraulic cylinder.

After processing the data of the hydraulic cylinder force and displacement in Fig. 7, and obtaining the hydraulic cylinder's stiffness-pressure curve shown in Fig. 8 , it shows that at low pressure $P<6 \mathrm{MPa}$, the amount of air greatly influences the hydraulic cylinder stiffness while the nonlinearity is obvious and the gradient of the stiffness variation is big. When the 
pressure $P>6 \mathrm{MPa}$, the influence of the air amount on the stiffness is small, while the linearity is obvious and the gradient of the stiffness variation is small.

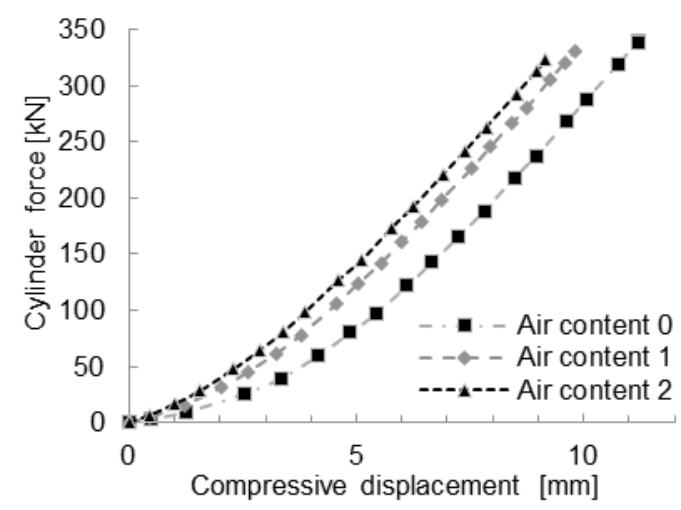

Fig. 7. The force-compressive displacement variation curve

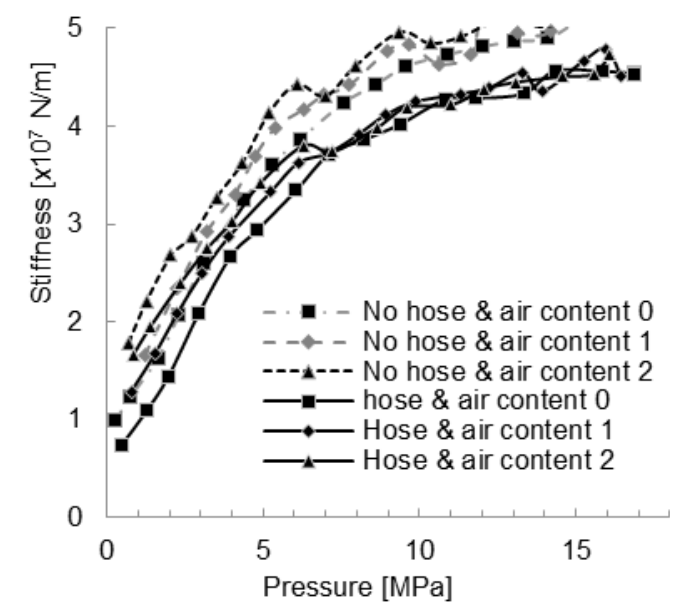

Fig. 8. The stiffness-pressure variation curve

Calculate the equivalent elasticity modulus of the hose based on the example of the experimental hydraulic cylinder. According to Fig. 8, under a stroke of $0.536 \mathrm{~m}$ and a pressure of $16 \mathrm{MPa}$, the value of the measured hydraulic cylinder stiffness without hose is $K_{\text {withouthose }}=4.7 \mathrm{e} 7 \mathrm{~N} / \mathrm{m}$, and the value of the measured hydraulic cylinder stiffness with hose is $K_{\text {withhose }}=4.24 \mathrm{e} 7 \mathrm{~N} / \mathrm{m}$. Based on Eq. (18), the stiffness generated by the hose hydraulic oil is $K_{\text {hose_oil }}=6.14 \mathrm{e} 8 \mathrm{~N} / \mathrm{m}$. By substituting these stiffness values into Eq. (16), and calculating with Eq. (12), the value of the equivalent elasticity modulus of the hose is $E_{h}=1.78 \mathrm{e} 10 \mathrm{~Pa}$. The equivalent elasticity modulus of the hose inferred in this way is smaller than the elasticity modulus of steel $E_{\text {steel }}=2.06 \mathrm{e} 11 \mathrm{~Pa}$, but is bigger than the bulk modulus of the hydraulic cylinder $E_{o}=1.49 \mathrm{e} 9 \mathrm{~Pa}$.

\subsection{Stiffness under Different Elongations and Analysis of Influence Factors}

To measure the hydraulic cylinder stiffness under different elongations and to research the influence of the elongation on that stiffness, the measured pressure and displacement data are analysed according to the following conditions: (1) The flexible hose is considered. (2) The hydraulic cylinder elongations are $0.138 \mathrm{~m}, 0.228 \mathrm{~m}, 0.381 \mathrm{~m}, 0.456 \mathrm{~m}$, and $0.536 \mathrm{~m}$, respectively. (3) Neglect the state of the air content and take the state without discharging air. After data processing, the hydraulic cylinder force and compressive displacement variation curve is obtained as shown in Fig. 9.

Under different elongations, the stiffness is clearly changed. As shown in Fig. 9, there is intersection between stroke curves at $0.138 \mathrm{~m}$, $0.228 \mathrm{~m}$ and $0.318 \mathrm{~m}$, which indicates that when the stroke of the hydraulic cylinder and the amount of the cylinder liquid volume are too small, other factors during the test including "the clearance of the hydraulic cylinder" or "the deformation of the rubber sealing" will have greater impact on the stiffness of the hydraulic cylinder than the air does. However, this phenomenon only occurs when the pressure is smaller than $2.5 \mathrm{MPa}$, and the results are normal when the pressure is greater than $2.5 \mathrm{MPa}$.

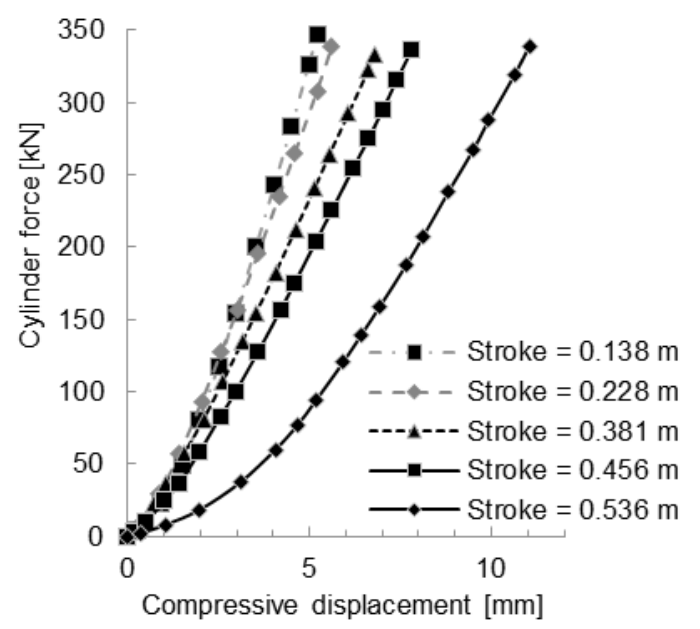

Fig. 9. The force-compressive displacement variation curve under different elongations

To further analyse the relation between the stiffness and the different elongations of the hydraulic cylinder, the data in Fig. 9 were processed and the stiffness-elongation curve obtained, as shown in Fig. 10. The figure highlights that: (1) The stiffness reduces dramatically with the increase of the cylinder 
elongation. (2) When $P<6 \mathrm{MPa}$, the gradient of the variation is big. When $P>6 \mathrm{MPa}$, the variation gradient of the hydraulic cylinder stiffness under each elongation is very small, and the linearity is obvious.

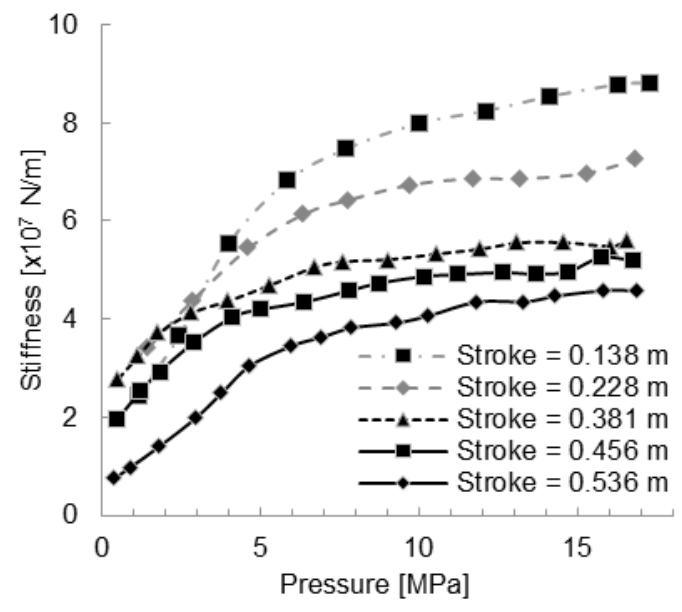

Fig. 10. The stiffness-elongation variation curve

\subsection{Level of Influence Analysis of Various Factors}

To obtain the level of influence of the various factors on the hydraulic cylinder stiffness, the experimental hydraulic cylinder can be taken as an example. According to Eqs. (2), (3), (7), (11), (12), and (16), the values of the hydraulic cylinder stiffness and the stiffness produced by each factor can be calculated respectively. Then the percentage of the stiffness produced by each factor relative to the hydraulic cylinder stiffness is also calculated. The level of influence of various factors on the hydraulic cylinder stiffness can thus be obtained and the results are shown in Table 2. It is concluded that: (1) the stiffness produced by the expansion of the metal pipe is small and can be neglected; (2) The influences of the flexible hose expansion stiffness, the axial stiffness of the piston rod and the cylinder barrel expansion stiffness on hydraulic cylinder stiffness cannot be neglected, especially for a short elongation of the hydraulic cylinder.

Table 2. The Level of influence of various factors

\begin{tabular}{cccccc}
\hline$L[\mathrm{~m}]$ & $K_{o}[\%]$ & $K_{r}[\%]$ & $K_{c}[\%]$ & $K_{p}[\%]$ & $K_{h}[\%]$ \\
\hline 0.138 & 72.90 & 10.05 & 10.81 & 0.50 & 6.24 \\
\hline 0.228 & 77.42 & 7.74 & 10.04 & 0.39 & 4.80 \\
\hline 0.381 & 81.68 & 5.56 & 9.31 & 0.28 & 3.45 \\
\hline 0.456 & 83.00 & 4.89 & 9.08 & 0.25 & 3.03 \\
\hline 0.536 & 84.09 & 4.33 & 8.89 & 0.22 & 2.69 \\
\hline
\end{tabular}

$L$ in table 2 is the hydraulic cylinder elongations.
According to the above analysis, the influence of cylinder sealing and the expansion of the metal pipe can be neglected during the hydraulic cylinder stiffness calculation. Therefore, the hydraulic cylinder stiffness calculation model Eq. (2) can be simplified as follows:

$$
\frac{1}{K}=\frac{1}{K_{o}}+\frac{1}{K_{r}}+\frac{1}{K_{c}}+\frac{1}{K_{h}}
$$

The levels of influence of each factor is given based on the experimental hydraulic cylinder. Since different hydraulic cylinder structures have different sizes, the levels need to be demonstrated according to Eqs. (2), (3), (7), (11), (12), and (16). After that, accept or reject each factor according to the accuracy requirements of the hydraulic cylinder stiffness.

\subsection{Comparative Analysis of Different Stiffness Models}

Eq. (1) and Eq. (18) proposed in this paper can be adopted to calculate the stiffness as an example for experimental hydraulic cylinders. After comparing and analysing the test results, as shown in Fig. 11, the errors between these two models, and test results are summarized in Table 3.

From Fig. 11 and Table 3 the calculated results of the stiffness model raised in this paper are better than those reported in the literature, and the average accuracy is improved by more than $15 \%$. Meanwhile, it is proven that: (1) when the elongation of the hydraulic cylinder is small, the stiffness error obtained when only considering the compressive deformation of hydraulic oil is very large, and the error reaches up to $40 \%$; (2) When the elongation of the hydraulic cylinder is sufficiently large, only the compressive deformation stiffness of the hydraulic oil needs to be considered. However, since the hydraulic cylinder is usually working in a reciprocating motion, the influences of the cylinder barrel expansion stiffness, the axial stiffness of the piston rod, and the flexible hose expansion stiffness cannot be neglected in the dynamic characteristic investigation of the hydraulic cylinder system or mechanical system.

Table 3. The error analysis of two models

\begin{tabular}{lcc}
\hline Stroke [m] & $\begin{array}{c}\text { Error of the model } \\
\text { from Eq. (1) [\%] }\end{array}$ & $\begin{array}{c}\text { Error of the new model } \\
\text { proposed by this paper [\%] }\end{array}$ \\
\hline 0.138 & 40.76 & 2.61 \\
\hline 0.228 & 29.63 & 0.37 \\
\hline 0.381 & 15.35 & -5.78 \\
\hline 0.456 & 9.18 & -9.39 \\
\hline 0.536 & 11.23 & -6.47 \\
\hline Average Error & 21.23 & -3.73 \\
\hline
\end{tabular}




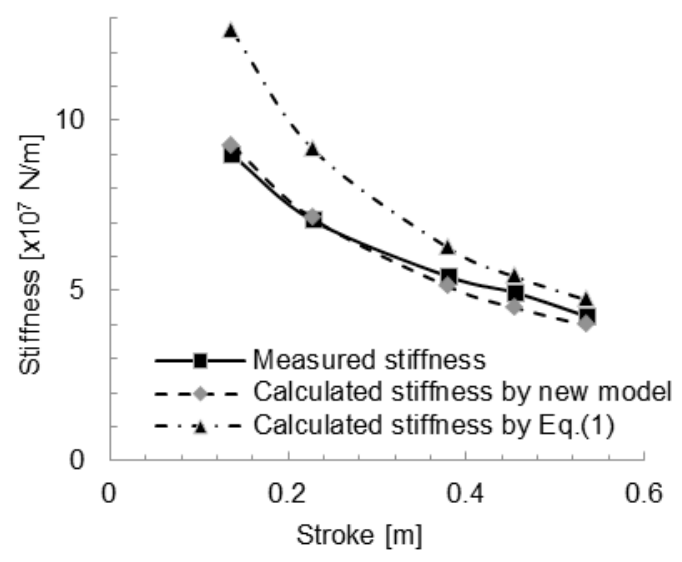

Fig. 11. The comparative analysis of theoretical and experimental hydraulic cylinder stiffness

\section{CONCLUSIONS}

To improve the calculation accuracy of the hydraulic cylinder stiffness, this paper comprehensively considered the influences of various factors on the stiffness of the hydraulic cylinder, and proposed a new stiffness model of the hydraulic cylinder whose calculation accuracy is higher than that in the published literature, which was proven by the tests. Meanwhile, the influences of different air contents on the bulk modulus and the hydraulic cylinder stiffness, as well as the influences of different elongations of the hydraulic cylinder on stiffness were experimentally investigated. The main research conclusions are as follows:

The compressive deformation of the hydraulic oil, the axial deformation of the piston rod, the expansion deformation of the cylinder barrel, and the expansion deformation of the flexible hose need to be considered for a hydraulic cylinder stiffness. While other factors like the air content in the oil, the expansion deformation of the metal pipe, and the seal of the hydraulic cylinder can be ignored.

The level of influence of each factor on the hydraulic cylinder stiffness is the following: the compressive deformation of the hydraulic oil about $80 \%$, the expansion deformation of the cylinder barrel is about $10 \%$, the axial deformation of the piston rod is about $6 \%$, and the expansion deformation of the flexible hose is about $3 \%$. Due to substantial differences for cylinders of different sizes, the ratio of the impact generated by various factors on the cylinder stiffness provided above is only applicable to the specific cases discussed in the paper.

When the pressure $P<6 \mathrm{MPa}$, the bulk modulus and the hydraulic cylinder stiffness are greatly influenced by the air content, while the nonlinearity is obvious and the variation gradient is large. However, when the pressure $P>6 \mathrm{MPa}$, the bulk modulus and the hydraulic cylinder stiffness are subtly influenced by the air content, while the linearity is obvious and the variation is small.

\section{ACKNOWLEDGEMENTS}

This work is supported by the China National Key Technology R\&D Program "Lightweight technology research and application on typical construction machinery" (2011BAF11B01). The authors wish to thank China National Earthmoving Machinery Engineering Research Center for providing experimental support. The authors also wish to thank Aaron Becker, Hydraulics Chief Engineer, North America New Technology R\&D, LiuGong Machinery Ltd, for his valuable suggestions. Many thanks also go to the reviewers of this paper for their helpful comments.

\section{REFERENCES}

[1] Laceklis-Bertmanis, J., Kakitis, A. Kronbergs, E., Repsa, E., Smits, M. (2010). Pressure oscillation in hydraulic hitchsystem during implement transport. Žemès Ūkio Inžinerija, Mokslo Darbai, vol. 42, no. 2/3, p. 22-31.

[2] Vollmer, F., Murrenhoff, H. (2002). Hydraulic linear actuators with high dynamic load stiffness. SAE Technical Paper, no. 2002-01-1496, D0I:10.4271/2002-01-1496.

[3] Tomski, L., Uzny, S. (2011). A hydraulic cylinder subjected to Euler's load in aspect of the stability and free vibrations taking into account discrete elastic elements. Archives of Civil and Mechanical Engineering, vol. 11, no. 3, p. 769-785, D0I:10.1016/S1644-9665(12)60115-0.

[4] Uzny, S. (2009). Free vibrations and stability of hydraulic cylinder fixed elastically on both ends. PAMM, vol. 9, no. 1, p. 303-304, DOI:10.1002/pamm.200910125.

[5] Dai, Y.F. (1999). The stiffness calculation of hydraulic cylinder. Nonferrous Metals Design, vol. 26, no. 1, 61-63. (in Chinese)

[6] Wang, L., Wu,B. (2007). Nonlinear dynamic characteristics of moving hydraulic cylinder. Journal of Mechanical Engineering, vol. 43, no. 12, p. 12-19, D0l:10.3901/jme.2007.12.012. (in Chinese)

[7] Khalil, M.K.B. (2009). Interactive analysis of closed loop electro-hydraulic control systems. 13th International Conference on Aerospace Sciences \& Aviation Technology, no. ASAT-13-HC-01.

[8] Zhong, Z., \& Yunxin, W. U. (2013). An equivalence method of the hydraulic cylinders in modal analysis of boom of truck mounted concrete pump. Machine Tool \& Hydraulics, vol. 41, no. 7, p. 5-8 (in Chinese)

[9] Jiang, W., Luo, X., Chen, X. (2016). Influence of structural flexibility on the nonlinear stiffness of hydraulic system. 
Advances in Mechanical Engineering, vol. 8, no. 8, DOI:10.1177/1687814016663806.

[10] Lei Tianjue (1998). The New Hydraulic Engineering Handbook, Beijing: Beijing Institute of Technology Press.

[11] Cho, B.H., Lee, H.W., Oh, J.S. (2002). Estimation technique of air content in automatic transmission fluid by measuring effective bulk modulus. International Journal of Automotive Technology, vol. 3, no. 2, p. 57-61.

[12] Ericson, L., Palmberg, J.0. (2008). Measurement of free air in the oil close to a hydraulic pump. Proceedings of the JFPS International Symposium on Fluid Power, vol. 2008, no. 7-3, p. 647-652, DOl:10.5739/isfp.2008.647.

[13] Manring, N.D. (1997). The effective fluid bulk-modulus within a hydrostatic transmission. Journal of Dynamic Systems, Measurement, and Control, vol. 119, no. 3, p. 462-466, D0I:10.1115/1.2801279.

[14] Fei, S., Kong, D. (2011). Bulk modulus measurement of hydraulic oil based on drop-hammer calibration device.
International Conference on Electric Information and Control Engineering, p. 213-216, D0I:10.1109/ICEICE.2011.5778375.

[15] Yang, H., Feng, B., Gong, G. (2011). Measurement of effective fluid bulk modulus in hydraulic system. Journal of Dynamic Systems, Measurement, and Control, vol. 133, no. 6, p. 061021, DOl:10.1115/1.4004783.

[16] Bureček, A., Hružík, L., Vašina, M. (2015). Determination of undissolved air content in oil by means of compression method. Strojniški vestnik - Journal of Mechanical Engineering, vol. 61, no. 7-8, p. 477-485, Dol:10.5545/sv-jme.2015.2471.

[17] Petrović, R., Živković, M., Rong, W.Z., Rakić, D., Slavković, R. (2014). Influence of air content entrained in fluid of a vane pump with double effect operating parameters. Tehnički vjesnik - Technical Gazette, vol. 21, no. 2,p. 401-407.

[18] Hydraulic fluid power - cylinders acceptance tests (ISO 10100:2001 + amd 1:2012).

[19] Hydraulic cylinder (JB/T 10205-2010). (in Chinese) 